\title{
Access to new antimicrobial 4-methylumbelliferone derivatives
}

\author{
MARWA ZAYANE ${ }^{\mathrm{a}}$, ANIS ROMDHANE ${ }^{\mathrm{a}, *}$, MEJDA DAAMI-REMADI $^{\mathrm{b}}$ and \\ HICHEM BEN JANNET ${ }^{\mathrm{a}}$ \\ ${ }^{a}$ Laboratoire de Chimie Hétérocyclique, Produits Naturels et Réactivité, Equipe: Chimie Médicinale et \\ Produits Naturels, Faculté des Sciences de Monastir, Université de Monastir, Avenue de l'Environnement, \\ 5019 Monastir, Tunisie \\ ${ }^{b}$ UR13AGR09, Production Horticole Intégrée au Centre Est Tunisien, Centre Régional des Recherches en \\ Horticulture et Agriculture Biologique de Chott-Mariem, Université de Sousse, 4042, Chott-Mariem, Tunisie \\ e-mail: anis_romdhane@yahoo.fr
}

MS received 4 April 2015; revised 16 June 2015; accepted 21 June 2015

\begin{abstract}
Synthesis of some novel coumarin esters has been accomplished through iodine-catalyzed method using 4-methylumbelliferone as the starting material. Condensation of hydrazide, which was obtained in two steps from 4-methylumbelliferone, with some arylaldhydes provided hydrazone derivatives, while the reaction with phenylthioisocyanate leads to the thiosemicarbazide that evolved into two new compounds. Finally, condensation reaction of hydrazide with three diketones afforded new pyrrole and pyrazole derivatives. Structures of all synthesized compounds were established on the basis of spectroscopic methods including ${ }^{1} \mathrm{H} \mathrm{NMR}$, ${ }^{13} \mathrm{C}$ NMR and ES-HRMS. They were finally tested for their antimicrobial activity and the structure-activity relationship was discussed.
\end{abstract}

Keywords. 7-hydroxy-4-methyl-coumarin; (4-methylumbelliferone); imine; triazole; thiadiazole; pyrazole; pyrrole; antimicrobial activity.

\section{Introduction}

Coumarins occupy an important place in the realm of natural products and organic synthesis. They constitute an important class of oxygen heterocycles and belong to the family of lactones having benzopyrane system. ${ }^{1}$ The coumarin skeleton is found in many natural products and is also used as an intermediate for the synthesis of specific and promising heterocyclic compounds, possessing a wide spectrum of biological activities such as anti-inflammatory, ${ }^{2}$ anti-tubercular, ${ }^{3}$ antioxidant, ${ }^{4}$ antimicrobial ${ }^{5}$ and anticoagulant agents. ${ }^{6}$ Many methods for the preparation of coumarin-based compounds have been reported. ${ }^{7-9}$ One of the main representative of this class is the 4-methylumbelliferone, used as a useful precursor for the preparation of such compounds. ${ }^{10-12}$

The study of nitrogen heterocyclic compounds has led a considerable development due to the revelation of their varied effects in diverse domains. In this context, pyrroles, pyrazoles, thiadiazoles and triazoles, and their derivatives are very attractive targets. They have been the subject of many chemical and biological studies on account of their pharmacological activity, such as

\footnotetext{
*For correspondence
}

antimicrobial, ${ }^{13}$ anticancer, ${ }^{14}$ antitubercular, ${ }^{15}$ antioxidant and anti-inflammatory agents. ${ }^{16}$

In view of the above observations and as a continuation of our previous work on the synthesis of new coumarin derivatives,${ }^{17}$ we report here the synthesis of a precursor $\mathbf{2}$ from the 4-methylumbelliferone $\mathbf{1}$ and its use as building blocks in the preparation of some novel coumarin esters 4 and other new derivatives 6-13 incorporating the coumarin and pyrrole, pyrazole, thiadiazole or triazole moieties and their antibacterial and antifungal activity.

\section{Experimental}

\subsection{General information}

All reactions were monitored by TLC using aluminium sheets of Merck silica gel $60 \mathrm{~F}_{254}, 0.2 \mathrm{~mm}$ thickness. Melting temperatures were determined on an electrothermal 9002 apparatus and were reported as uncorrected. NMR spectra were recorded on a Bruker AC-300 spectrometer at $300 \mathrm{MHz}\left({ }^{1} \mathrm{H}\right)$ and $75 \mathrm{MHz}$ $\left({ }^{13} \mathrm{C}\right)$. All chemical shifts are reported as $\delta$ values (ppm) relative to residual non- deuterated solvent. Mass spectra were obtained with ESI-TOF (LCT, Waters) using the reflectron mode in the positive ion mode. 


\subsection{Synthesis}

2.2a Preparation of ethyl 2 -(4-methyl-2-oxo- $2 \mathrm{H}$ chromen-7-yloxy) acetate 2: Equimolar solution (15 $\mathrm{mmol}$ ) of 7-hydroxy-4-methylcoumarin 1, anhydrous potassium carbonate and ethyl chloroacetate was refluxed in dry DMF $(40 \mathrm{~mL})$ with continuous stirring for $5 \mathrm{~h}$ under argon atmosphere. After addition of ice water, the solid formed was collected by filtration, dried and recrystallized from ethanol to give compound $\mathbf{2}$.

2.2b Preparation of 2-(4-methyl-2-oxo-2H-chromen7-yloxy) acetic acid 3: A solution of compound 2 (15 $\mathrm{mmol})$ and $\mathrm{NaOH} 5 \%(15 \mathrm{~mL})$ was refluxed in ethanol $(30 \mathrm{~mL}$ ) for $2 \mathrm{~h}$ in open air. After cooling, the mixture was acidified with $\mathrm{HCl}(6 \mathrm{M})$. The precipitate obtained was filtered, washed several times with cold water and recrystallized from ethanol to give the acid $\mathbf{3}$.

2.2c General procedure for preparation of esters 4: A mixture of compound $\mathbf{3}(1 \mathrm{mmol})$ and the appropriate alcohol $(10 \mathrm{~mL})$ was refluxed in the presence of a catalytic amount of iodine $\left(\mathrm{I}_{2}\right)$ for $1 \mathrm{~h} 30$ min under argon atmosphere. After removal of the excess of alcohol, the residue was extracted with diethyl ether and the organic phase was washed with a sodium thiosulfate solution $(0.1 \mathrm{M})$ and distilled water. After decantation, the organic phase was dried over sodium sulfate and concentrated. The residue obtained was purified by silica gel column to obtain the esters $\mathbf{4 a - f}$.

2.2d Preparation of 2-(4-methyl-2-Oxo-2H-chromen7-yloxy) acetohydrazide 5: Compound 2 (15 mmol) was dissolved in a solution containing ethanol $(30 \mathrm{~mL})$ and hydrazine hydrate $(5 \mathrm{~mL})$ and the mixture was left under reflux for $2 \mathrm{~h}$ in open air. The precipitate formed during the reaction was filtered hot and then recrystallized in ethanol/water (90/10) to give compound 5.

2.2e General procedure for preparation of imines 6 : Equimolar solution (1.2 mmol) of 2-(4-methyl-2-Oxo$2 \mathrm{H}$-chromen-7-yloxy)acetohydrazide 5 and the aromatic aldehyde was refluxed in dry ethanol $(15 \mathrm{~mL})$ for $1 \mathrm{~h}$ under argon atmosphere. The white precipitate formed during the reaction was filtered hot and then recrystallized in ethanol to afford compounds 6a-c.

2.2f Preparation of 2-(2-((4-methyl-2-oxo-2H-chromen7-yl)oxy)acetyl)-N-phenylhydrazinecarbothioamide 7:
A mixture of compound 5 (1 mmol) and phenyl isothiocyanate $(1 \mathrm{mmol})$ in dry dioxane $(15 \mathrm{~mL})$ was heated to reflux for $24 \mathrm{~h}$ under argon atmosphere. The crude product thus obtained was filtered to give compound 7 .

2.2g Preparation of 4-methyl-7-((4-phenyl-5-thioxo4,5-dihydro-1H-1,2,4-triazol-3-yl) methoxy)-2H-chromen-

2-one 8: A mixture of 7 (1 mmol) and a $2 \%$ aq. solution of $\mathrm{NaOH}(6 \mathrm{~mL})$ was heated to reflux for $4 \mathrm{~h}$ in open air. Then, the solution was neutralized with $\mathrm{AcOH}$, extracted by AcOEt and purified by silica gel column to finally produce compound $\mathbf{8}$.

2.2h Preparation of 4-methyl-7-((5-(phenylamino)1,3,4-thiadiazol-2-yl)methoxy)-2H-chromen-2-one 9: A solution of 7 (1 mmol) in conc. $\mathrm{H}_{2} \mathrm{SO}_{4}(4 \mathrm{~mL})$ was kept at room temperature for one day in open air. After neutralization of the solution with diluted $\mathrm{NH}_{4} \mathrm{OH}$, the solid product was filtered off and dried to give compound 9.

\section{$2.2 \mathrm{i}$ General procedure for preparation of compounds}

10-13: Equimolar solution of compound 5 (1.2 mmol) and diketone was refluxed in dry ethanol $(15 \mathrm{~mL})$ for $1 \mathrm{~h}$ 30 min under argon atmosphere. The precipitate formed during the reaction was filtered and then purified by silica gel column to finally produce the compounds 10-13.

\subsection{Biological activity}

2.3a Antibacterial activity: The purified products were screened for their antibacterial activity by the agar disc diffusion method. ${ }^{18}$ NA medium cooled at $45^{\circ} \mathrm{C}$ was supplemented with a bacterial suspension $\left(10^{6} \mathrm{CFU} / \mathrm{mL}\right)$ and poured into Petri plates. After solidification, sterile Whatman paper discs (diameter $6 \mathrm{~mm}$ ) were placed at the surface of the culture medium and 20 $\mu \mathrm{L}(1000 \mu \mathrm{g} / \mathrm{mL})$ of the product dissolved in DMSO was dropped onto each disc. The negative control plates had no product added to the filter paper whereas in the positive control plates, discs were impregnated with the same volume of ampicillin solution $(5 \mathrm{mg} / \mathrm{mL})$. The treated Petri dishes were incubated at $25^{\circ} \mathrm{C}$ for $48 \mathrm{~h}$. The antibacterial activity was evaluated by measuring the diameter of the inhibitory zones formed around the discs. The experiment was replicated twice.

2.3b Antifungal activity: Aspergillus flavus, Aspergillus niger and Penicillium italicum were used for the screening of antifungal activity of the products tested by using 
the disc diffusion method. ${ }^{19}$ A conidial suspension of the tested fungi was prepared $\left(10^{4}-10^{5} \mathrm{CFU} / \mathrm{mL}\right)$ and added to PDA medium cooled at $45^{\circ} \mathrm{C}$ and poured uniformly into Petri plates (diameter $90 \mathrm{~mm}$ ). Sterilized paper discs (6 mm, Whatman No. 1 filter paper) were impregnated with $20 \mu \mathrm{L}(1000 \mu \mathrm{g} / \mathrm{mL})$ of the product dissolved in DMSO and placed on the culture plates whereas the negative control plates had no product added to the filter paper. In the positive control plates, discs were imbibed with the same volume of a carbendazim suspension $(0.5 \mathrm{mg} / \mathrm{mL})$. The diameter of the inhibition zone $(\mathrm{mm})$ around the disc was measured after incubation at $25^{\circ} \mathrm{C}$ for 4 days and compared with control. The test was performed in triplicate.

\section{Results and Discussion}

\subsection{Chemistry}

According to the literature, ${ }^{20}$ the reaction of 4methylumbelliferone $\mathbf{1}$ with ethyl chloroacetate upon refluxing in dry DMF using potassium carbonate afforded the key intermediate $\mathbf{2}$ which was treated with a solution of $\mathrm{NaOH}(5 \%)$ in ethanol and followed by protonation, ${ }^{21}$ to give 2-(4-methyl-2-oxo-2H-chromen7-yloxy)-acetic acid 3. The structure of this compound was identified by ${ }^{1} \mathrm{H}$ and ${ }^{13} \mathrm{C}$ NMR spectra. Esterification of compound $\mathbf{3}$ with a series of alcohols using iodine as catalyst, ${ }^{22,23}$ led to the formation of new esters 4a-f (scheme 1).

The structures of compounds 4a-f were characterized by ${ }^{1} \mathrm{H}$ NMR showing new signals in the region (0.85-4.97 ppm) attributed to protons introduced by the used alcohol. Further, the ${ }^{13} \mathrm{C}$ NMR spectra of these compounds exhibited the presence of new signals at (9.6-78.9 ppm) relative to the carbons also introduced by the used alcohol.

Mechanistically, being Lewis acid, $\mathrm{I}^{+}$makes a strong covalent bond with carbonyl function of acid $\mathbf{3}$ and then, the non-isolable intermediate $\mathbf{3}^{\prime}$ is subjected to nucleophilic attack by the alcohol used on the electrondeficient carbon, followed by an intramolecular rearrangement to give new coumarin esters 4a-f along with regeneration of the catalyst (scheme 2).

Our approach to the target coumarin compounds 613 was started with the synthesis of the precursor 5 via the condensation between the coumarin ester $\mathbf{2}$ and an excess of hydrazine hydrate under reflux of ethanol. ${ }^{24}$

The above-mentioned precursor $\mathbf{5}$ which contains the hydrazide moiety represents a class of intermediates

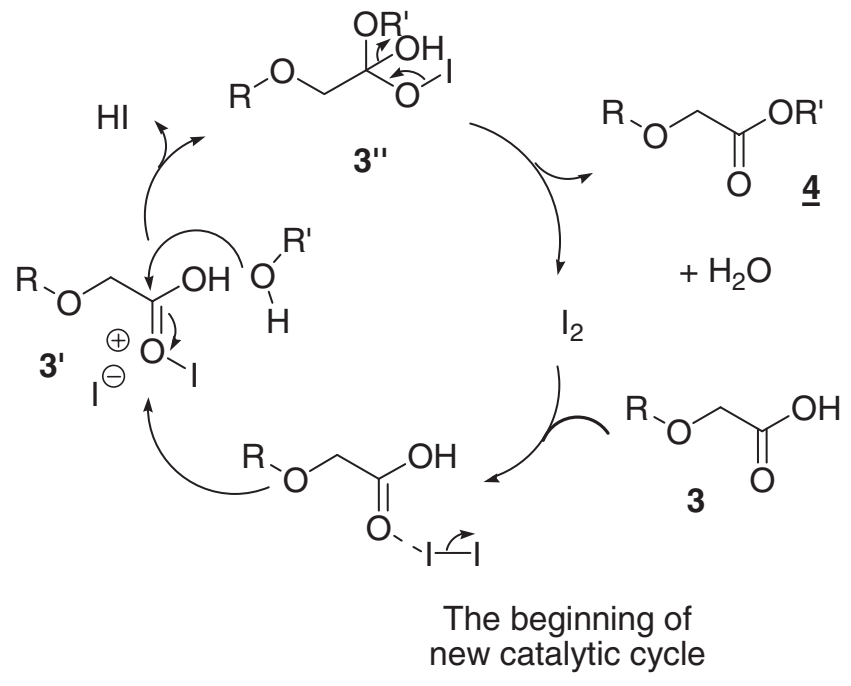

Scheme 2. Proposed mechanism for iodine catalyzed esterification.<smiles>Cc1cc(=O)oc2cc(O)ccc12</smiles>

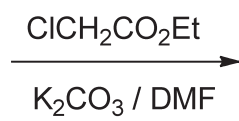

1<smiles>[R]OC(=O)COc1ccc2c(C)cc(=O)oc2c1</smiles>

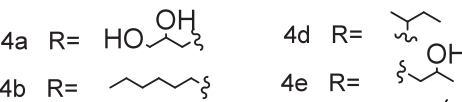

4c $R=\sim_{4 f} R=\bigcup^{\xi}$

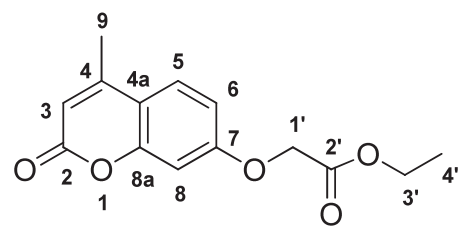

$2(70 \%)$

1) $\mathrm{NaOH}(5 \%)$

2) $\mathrm{HCl}(6 \mathrm{M})$

3) $\mathrm{I}_{2}, \mathrm{ROH}$ (excess)

Reflux

Scheme 1. Synthetic route of esters 4a-f. 
which are known to be highly reactive and used for the synthesis of heterocyclic compounds which incorporate five- and six-membered rings containing nitrogen. ${ }^{25}$ The ${ }^{1} \mathrm{H}$ NMR spectrum of compound $\mathbf{5}$ showed the disappearance of the signals relative to the alkoxy protons of the ester and the appearance of new signals, attributable to the $\mathrm{NH}$ and $\mathrm{NH}_{2}$ protons at 9.45 and 4.38 ppm, respectively.

Firstly, refluxing 5 with different aromatic aldehydes in ethanol ${ }^{26}$ was conducted until TLC indicated that the starting materials have been completely converted into products $\mathbf{6 a - c}$ which were confirmed by their ${ }^{1} \mathrm{H}$ and ${ }^{13} \mathrm{C}$ NMR data (scheme 3).

Compounds 6a-c were established by their ${ }^{1} \mathrm{H}$ NMR spectra showing the disappearance of $\mathrm{NH}_{2}$ protons at $4.38 \mathrm{ppm}$ and the appearance of a new singlet at 8.50$8.58 \mathrm{ppm}$ attributable to the $\mathrm{N}=\mathrm{CH}$ proton in addition to the signals relative to protons introduced by the coumarin hydrazide $\mathbf{5}$ and the used aromatic aldehydes.

The ${ }^{13} \mathrm{C}$ NMR spectra of compounds 6a-c displayed in particular a new signal at 144.1-146.8 ppm attributable to the iminic carbon $\mathrm{CH}=\mathrm{N}$ in addition to the new signals at $109.2-153.3 \mathrm{ppm}$ relative to the aromatic carbons introduced by the used aldehydes.

According to the literature, ${ }^{26,27}$ reaction of compound 5 with phenylisothiocyanate in refluxing dioxane gave the thiosemicarbazide 7 (scheme 4).

The ${ }^{1} \mathrm{H}$ NMR spectrum of the compound 7 exhibited essentially two new signals due to -NHCSNH- at 9.69-10.33 ppm. Further, the ${ }^{13} \mathrm{C}$ NMR spectrum of this compound showed the presence of new signals corresponding to the aromatic carbons introduced by the phenylisothiocyanate and a signal at $181.1 \mathrm{ppm}$ assigned to the $\mathrm{C}=\mathrm{S}$ carbon.
A survey of the literature indicates that the reaction of hydrazides with isothiocyanates is a typical procedure applied for the preparation of 1,2,4-triazole-3-thiones or 1,3,4-thiadiazoles. ${ }^{19}$ The two-step reactions led initially to the thiosemicarbazide 7 , which subsequently undergoes cyclocondensation under acidic or basic reaction conditions. ${ }^{27}$ Using these methods, the intermediate 7 was converted into triazolthione $\mathbf{8}(35 \%)$ by heating in aqueous $\mathrm{NaOH}$ solution and into thiadiazole $9(82 \%)$ by stirring in the presence of a solution of conc. $\mathrm{H}_{2} \mathrm{SO}_{4}$ at room temperature (scheme 4).

The ${ }^{1} \mathrm{H}$ NMR spectra of compounds 8 and $\mathbf{9}$ exhibited a singlet relative to $\mathrm{NH}$ proton at 7.01 and $4.03 \mathrm{ppm}$, respectively, and these signals were in good agreement with the expected cyclization reaction. The observation of a new signal at $166.9 \mathrm{ppm}$ in the ${ }^{13} \mathrm{C}$ NMR spectrum of compound $\mathbf{8}$ attributable to the thiocarbonyl function added to the disappearance of those corresponding to the amide and thiosemicarbazide carbonyl functions in the precursor $\mathbf{7}$ confirmed the identified structure.

The disappearance of the amide carbonyl and the thiocarbonyl signals from the ${ }^{13} \mathrm{C}$ NMR spectrum of compound 9 was in concordance with the proposed structure.

With the aim to continue the study of the reactivity of the hydrazide $\mathbf{5}$, we reacted it with a series of diketones (pentane-2,4-dione, hexane-2,5-dione and 1phenyl-1,3-butanedione) in refluxing ethanol according to the literature ${ }^{13}$ to produce the corresponding pyrrole $\mathbf{1 0}$ and pyrazole 11-13 derivatives, respectively. Despite the low yield $(50 \%)$ of the formation of the 5-hydroxy3,5-dimethyl-4,5-dihydro- $1 H$-pyrazole 11, we did not notice its dehydration that normally leads to the corresponding 3,5-dimethyl-1 $H$-pyrazol. This finding can be

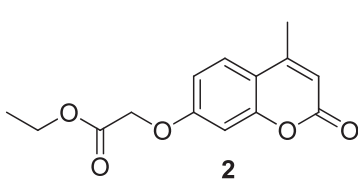

2

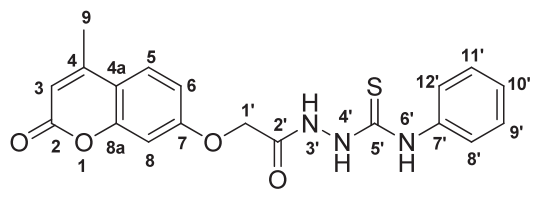

$7(86 \%)$

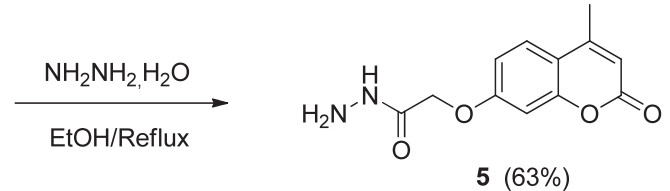

$5(63 \%)$
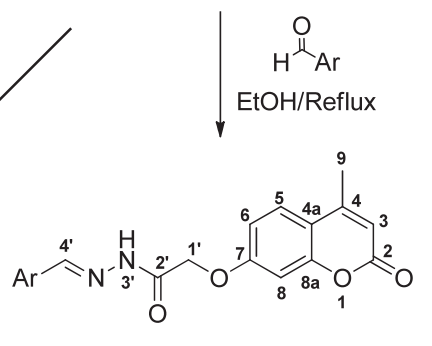

6a-c $(80-85 \%)$

6a $\mathrm{Ar}=p-\mathrm{N}(\mathrm{Me})_{2} \mathrm{C}_{6} \mathrm{H}_{4}$ 6b $\mathrm{Ar}=3,4-\mathrm{di}(\mathrm{MeO}) \mathrm{C}_{6} \mathrm{H}_{3}$ 6c $\mathrm{Ar}=p-\mathrm{tBuC}_{6} \mathrm{H}_{4}$

Scheme 3. Synthetic route of compounds 6-7. 


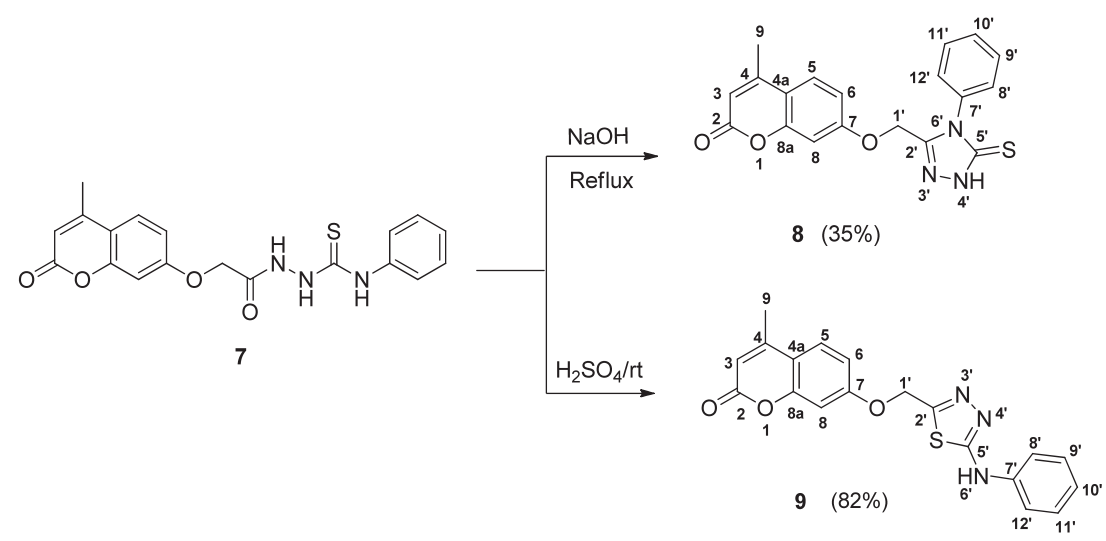

Scheme 4. Synthetic route of triazolethione 8 and thiadiazole 9.<smiles>CCCC(C)C(C)=O</smiles><smiles>Cc1cc(=O)oc2cc(OCC(=O)Nn3c(C)ccc3C)ccc12</smiles>

$10(45 \%)$

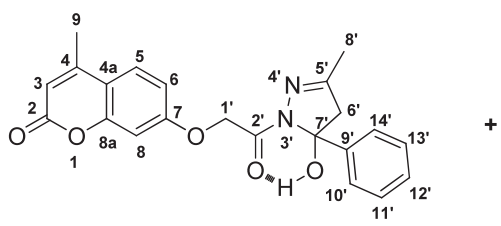

$12(60 \%)$<smiles>Cc1cc(=O)oc2cc(OCC(=O)NN)ccc12</smiles><smiles>CCC(=O)CC(=O)c1ccccc1</smiles>

$\downarrow$<smiles>Cc1cc(=O)oc2cc(OCC3=NN4COC3(C)CC4(C)C)ccc12</smiles>

$11(55 \%)$

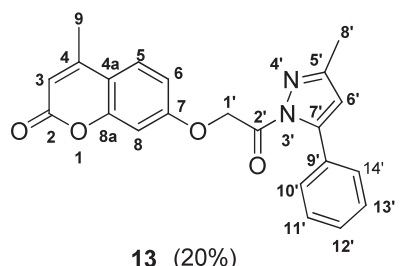

Scheme 5. Synthetic route of compounds 10-13.

explained by the hydrogen bond between the $\mathrm{OH}$ group and the carbonyl function leading to the formation of a stable pseudo-six-membered ring.

On the other hand, the treatment of the hydrazide 5 with 1-phenyl-1,3-butanedione led to primarily the 5-hydroxy-3,5-dimethyl-4,5-dihydro-1H-pyrazole 12 together with its di-dehydrated analogue 13. This result can be explained by the presence of the phenyl group which causes a steric hindrance inhibiting the formation of a hydrogen bond and stabilizes the molecule by the extensive conjugation with the pyrazole system (scheme 5).

The structure of compound $\mathbf{1 1}$ was evidenced via its ${ }^{1} \mathrm{H}$ NMR spectrum showing the appearance of a new signal attributable to the $\mathrm{OH}$ proton at $4.26 \mathrm{ppm}$ which provides no correlation in the CHcorr spectrum and two doublets at 2.82 and $3.03 \mathrm{ppm}(J=18.6 \mathrm{~Hz})$ related to $\mathrm{CH}_{2}$ group $\left(\mathrm{H}_{6^{\prime}}\right)$ and the disappearance of the signals related to the $\mathrm{NH}$ and $\mathrm{NH}_{2}$ protons at 9.45 and $4.38 \mathrm{ppm}$, respectively. The ${ }^{13} \mathrm{C}$ NMR spectrum, the same compound showed the appearance of new signals related to carbons $\mathrm{C}_{6^{\prime}}$ and $\mathrm{C}_{7^{\prime}}$ at 51.2 and $144.1 \mathrm{ppm}$, respectively.

Similarly, the ${ }^{1} \mathrm{H}$ NMR spectrum of compound $\mathbf{1 0}$ showed the appearance of a singlet related to the $\mathrm{NH}$ proton at $8.69 \mathrm{ppm}$ and the disappearance of the signal related to the $\mathrm{NH}_{2}$ protons at $4.38 \mathrm{ppm}$. Analysis of ${ }^{13} \mathrm{C}$ NMR spectrum of this compound showed the appearance of new signals attributable to the magnetically equivalent carbons $\left(\mathrm{C}_{6^{\prime}+} \mathrm{C}_{7^{\prime}}\right)$ at $120.6 \mathrm{ppm}$.

The ${ }^{1} \mathrm{H}$ NMR spectrum of compound $\mathbf{1 2}$ showed the disappearance of the signals of the $\mathrm{NH}$ and $\mathrm{NH}_{2}$ protons at 9.45 and $4.38 \mathrm{ppm}$, respectively and the appearance of a singlet assigned to the $\mathrm{OH}$ proton at $7.03 \mathrm{ppm}$ 
and two doublets in the region 3.03-3.18 ppm corresponding to the non-equivalent methylene protons $\left(\mathrm{H}_{6^{\prime} \mathrm{a}}\right.$, $\left.\mathrm{H}_{6^{\prime} \mathrm{b}}\right)$. The ${ }^{13} \mathrm{C}$ NMR spectrum of this compound displayed new signals at 55.2 and $143.4 \mathrm{ppm}$ attributable to $\mathrm{C}_{6^{\prime}}$ and $\mathrm{C}_{7^{\prime}}$, respectively. Compound $\mathbf{1 3}$ obtained after dehydratation of pyrazole 12 was confirmed by its ${ }^{1} \mathrm{H}$ NMR spectrum showing the disappearance of the singlet relative to the $\mathrm{OH}$ proton at $7.03 \mathrm{ppm}$ and the appearance of a new singlet at $6.97 \mathrm{ppm}$ relative to $\mathrm{H}_{6}$. Further, the ${ }^{13} \mathrm{C}$ NMR spectrum of the pyrazole $\mathbf{1 3}$ showed essentially two new signals at 108.2 and 144.5 ppm attributable to the carbons $\mathrm{C}_{6^{\prime}}$ and $\mathrm{C}_{7^{\prime}}$, respectively.

The ESI-HRMS of all the synthesized compounds showed the correct protonated molecular ion peaks $[\mathrm{M}+\mathrm{H}]^{+}$which are compatible with the proposed structures.

\subsection{Biological activity}

All the synthesized compounds have been evaluated for their antibacterial and antifungal activities activities.

3.2a Antibacterial activity: The antibacterial activity of these compounds was performed against a panel of microorganisms: Pseudomonas savatanoi, Pseudomonas huttiensis and Agrobacterium tumefasciens. The results given in table 1 shows that most compounds have displayed acceptable antibacterial activity against

Table 1. Antibacterial activity of the synthesized compounds.

\begin{tabular}{lccc}
\hline \multicolumn{4}{c}{ Inhibition zone diameter (mm) } \\
\hline Product & $\begin{array}{c}\text { Pseudomonas } \\
\text { savatanoi }\end{array}$ & $\begin{array}{c}\text { Pseudomonas } \\
\text { huttiensis }\end{array}$ & $\begin{array}{c}\text { Agrobacterium } \\
\text { tumefasciens }\end{array}$ \\
\hline $\mathbf{4 a}$ & 8.5 & - & - \\
$\mathbf{4 b}$ & 11 & - & 10 \\
$\mathbf{4 c}$ & 10 & - & - \\
$\mathbf{4 d}$ & - & - & 12 \\
$\mathbf{4 e}$ & 13 & - & - \\
$\mathbf{4 f}$ & 10 & - & - \\
$\mathbf{6 a}$ & - & 11 & - \\
$\mathbf{6 b}$ & 12 & 9 & - \\
$\mathbf{6 c}$ & - & 8.5 & - \\
$\mathbf{7}$ & 11 & - & - \\
$\mathbf{8}$ & 9 & - & 7.5 \\
$\mathbf{9}$ & 9.5 & - & - \\
$\mathbf{1 0}$ & - & - & 9 \\
$\mathbf{1 1}$ & - & - & 10.5 \\
$\mathbf{1 2}$ & 10.5 & - & 11 \\
$\mathbf{1 3}$ & 9.5 & - & - \\
Ampicilin & 22 & 18 & 25 \\
DMSO & - & - & - \\
\hline- & - & &
\end{tabular}

P. savatanoi. Thus, compounds $4 \mathrm{~b}(\mathrm{IZ}=11 \mathrm{~mm})$ and $4 \mathbf{e}$ $(\mathrm{IZ}=13 \mathrm{~mm})$ were most active against this strain. We noticed that the presence of two free hydroxyl groups in compound $4 \mathbf{a}$ has not improved this activity. The results showed that only compounds $\mathbf{6 a}, \mathbf{6 b}$ and $\mathbf{6 c}$ exhibited activity against $P$. huttiensis with IZ values of 11,9 and $8.5 \mathrm{~mm}$, respectively. This finding shows that the presence of the dimethylamino group in para position of the aromatic system introduced by the aldehyde used seems at the origin of this relatively high activity.

It was found that the conversion of compound 7 into triazole thione $\mathbf{8}$ and thiadiazole $\mathbf{9}$ via the thiosemicarbazide function did not improve its activity towards $P$. savatanoi ( $\mathrm{IZ}=11,9$ and $9.5 \mathrm{~mm}$, respectively). The thiosemicarbazide function in compound 7 could contribute to its activity. On the other hand, these compounds did not show any activity against $P$. huttiensis and only compound $\mathbf{8}$ exhibited a low activity towards A. tumefasciens $(\mathrm{IZ}=7.5 \mathrm{~mm})$.

Pyrazole and pyrrole derivatives 10-12 were found to be active towards A. tumefasciens. The activity of compounds 11 and 12 could be explained by the presence in each one of the tertiary alcohol and of the asymmetric center $\mathrm{C}_{8^{\prime}}$, whereas the activity of compound $\mathbf{1 0}$ against the same strain $(\mathrm{IZ}=9 \mathrm{~mm})$ could be due to the pyrrole and the acetamide moieties. The presence of the pyrazole and the extent of its conjugation with the phenyl group in compound $\mathbf{1 3}$ could explain the loss in activity against the same bacterium. The activity of compounds $12(\mathrm{IZ}=10.5 \mathrm{~mm})$ and $\mathbf{1 3}(\mathrm{IZ}=9.5 \mathrm{~mm})$ against $P$. savatanoi could be due to the presence of the common $N$-2-oxoethoxy and phenyl systems (table 1 ).

3.2b Antifungal activity: The antifungal activity of the synthesized compounds was tested against three fungal strains: Aspergillus flavus,A. niger and Penicillium italicum. According to the results given in table 2, most synthesized compounds showed variable degrees of inhibition against $A$. niger. However, compounds 4ad showed practically the most relatively high activity against this fungus ( $\mathrm{IZ}=10-13 \mathrm{~mm})$. This finding could be explained by the nature of the alcohols used in the preparation of these esters comparatively to $\mathbf{4 f}(\mathrm{IZ}=9.5$ $\mathrm{mm}$ ) and $\mathbf{4 e}$ (not active). Similarly, the activity of compounds $\mathbf{6 a - c}$ against the same fungus varies depending on the aryl group introduced by each aldehyde used in their preparation.

The results mentioned in table 2 showed that compound $\mathbf{7}$ and its derivative $\mathbf{8}$ (triazole thione) display the same activity $(\mathrm{IZ}=9.5 \mathrm{~mm})$ against $A$. niger, whereas compound 9 (thiadiazole) was found to be inactive. This result could be explained by the loss of the thiosemicarbazide skeleton in this compound but 
Table 2. Antifungal activity of the synthesized compounds.

\begin{tabular}{lccc}
\hline \multicolumn{4}{c}{ Inhibition zone diameter $(\mathrm{mm})$} \\
\hline Product & $\begin{array}{c}\text { Aspergillus } \\
\text { flavus }\end{array}$ & $\begin{array}{c}\text { Aspergillus } \\
\text { niger }\end{array}$ & $\begin{array}{c}\text { Penicillium } \\
\text { italicum }\end{array}$ \\
\hline $\mathbf{4 a}$ & 9 & 12 & 7.5 \\
$\mathbf{4 b}$ & - & 10 & - \\
$\mathbf{4 c}$ & - & 13 & 10 \\
$\mathbf{4 d}$ & 9 & 12 & - \\
$\mathbf{4 e}$ & 10 & - & - \\
$\mathbf{4}$ & 9 & 9.5 & - \\
$\mathbf{6}$ & - & 9 & - \\
$\mathbf{6}$ & - & 10.5 & - \\
$\mathbf{6}$ & - & 11 & 9.5 \\
$\mathbf{7}$ & 7 & 9.5 & - \\
$\mathbf{8}$ & 7.5 & 9.5 & - \\
$\mathbf{9}$ & - & - & - \\
$\mathbf{1 0}$ & - & 10 & - \\
$\mathbf{1 1}$ & - & 9.5 & - \\
$\mathbf{1 2}$ & - & 11 & - \\
$\mathbf{1 3}$ & 7.5 & 11 & - \\
FONG & 37 & 32.5 & 40.5 \\
DMSO & - & - & - \\
\hline
\end{tabular}

FONG: Carbendazime $0.5 \mathrm{mg} / \mathrm{mL}$

- no inhibition zone observed.

another side is kept in compound $\mathbf{8}$ in a cyclized form. Compounds 10, 11, 12 and $\mathbf{1 3}$ displayed activity towards $A$. niger with $\mathrm{IZ}$ values of 10, 9.5, 11 and 11 $\mathrm{mm}$, respectively. However, the pyrrole and the pyrazol moieties have certainly contributed to this activity. $P$. italicum did not show any sensitivity against most tested compounds and certain of these $(\mathbf{4 a}, \mathbf{4 d - f}, \mathbf{7}, \mathbf{8}$, 13) exhibited moderate to low activity towards A. flavus.

\section{Conclusion}

In conclusion, this work reports the synthesis of 2(4-methyl-2-oxo-2H-chromen-7-yloxy) acetic acid $\mathbf{3}$ in two steps starting from 4-methylumbelliferone, and its use as a key intermediate to access new coumarin esters 4a-f. In the second part of this work, we described the successful synthesis of new coumarin hydrazones 6a-c, sulfur compounds 7-9 and new pyrrole and pyrazole compounds $\mathbf{1 0 - 1 3}$, via the condensation reaction of 2-(4-methyl-2-oxo- $2 \mathrm{H}$-chromen7-yloxy) acetohydrazide 5, previously prepared from 4-methylumbelliferone, with arylaldehyde, phenylthioisocyanate and three diketones, respectively. The antimicrobial activity of the newly synthesized compounds was evaluated.

\section{Supplementary Information}

${ }^{1} \mathrm{H}$ and ${ }^{13} \mathrm{C}$ NMR spectra and analytical data for all new synthesized compounds are available at www.ias.ac.in/ chemsci.

\section{Acknowledgements}

The authors are grateful to Miss Amna Benzarti, NMR service at the Faculty of Monastir, University of Monastir for the NMR analysis and to the Ministry of Higher Education and Scientific Research of Tunisia for financial support.

\section{References}

1. Curini M, Cravotto G, Epifano F and Giannone G 2006 Curr. Med. Chem. 13199

2. Bansal Y, Sethi P and Bansal G 2013 Med. Chem. Res. 223049

3. Kawate T, Iwase N, Shimizu M, Stanley S A, Wellington S, Kazyanskaya E and Hung D T 2013 Bioorg. Med. Chem. Lett. 236052

4. Gacche R N and Jadhav S G 2012 J. Exp.Clin. Med. 4 165

5. Nagamallu R and Kariyappa A K 2013 Bioorg. Med. Chem. Lett. 236406

6. Weigt S, Huebler N, Strecker R, Braunbeck $\mathrm{T}$ and Broschard T H 2012 Reprod. Toxicol. 33133

7. Gammon D W, Hunter R and Wilson S A 2005 Tetrahedron 6110683

8. Santana L, Uriarte E, González-Díaz H, Zagotto G, Soto-Otero R and Méndez-Alvarez E $2006 \mathrm{~J}$. Med. Chem. 491149

9. Messaoudi S, Peyrat J F, Brion J D and Alami M 2010 Adv. Synt. Catal. 3521677

10. Ramesh P, Das A T, Mohandass P and Nagasathya R 2008 Indian J. Chem. 471447

11. Ganesh R K, Prarthana V R, Sandeep G, Saurabh A, Arunima V, Atin K and Suresh T 2010 Lett. Drug. Des. Discov. 746

12. Kumar T, Dewangan D, Alexander A, Nagori K and Tripathi D K 2011 Asian J. Biochem. Pharm. Res. 2 2231

13. Refat H M and Fadda A A 2013 Eur. J. Med. Chem. 70 419

14. Al-Tel T H 2010 Eur. J. Med. Chem. 104615

15. Joshi S D, Vagdevi H M, Vaidya V P and Gadaginamath G S 2008 Eur. J. Med. Chem. 431989

16. Bhalgat C M, Ali M I, Ramesh B and Ramu G 2014 Arabian. J. Chem. 7986

17. Zghab I, Trimeche B, Touboul D and Ben Jannet H 2014 C. R. Chimie. 17171

18. Marmonier A 1987 In Antibiotiques Technique de diffusion en gélose méthode des disques. Bactériologie médicale Techniques usuelles (SIMEP SA-Paris, France) pp. 4, 237-243

19. Barry A L and Thornberry C 1991 In Manual of Clinical Microbiology A H Ballows, W J Jr. Hausler, K L Herrman, H J Isenberg and Shadomy (Eds.) 5th ed. (American Society for Microbiology Press: Washington, DC) pp. $1117-1125$ 
20. Hamdi N, Al-Ayed A S, Said R B and Fabienne A 2012 Molecules 179321

21. Al-Amiery A, Musa A Y, Kadhum A A H and Mohamad A B 2011 Molecules 166833

22. Ramalinga K, Vijayalakshmi P and Kaimal T N B 2002 Tetrahedron Lett. $\mathbf{4 3} 879$

23. Vrazic J D and Zupan M 2009 Tetrahedron Lett. 502347
24. Abdel-Aziz H A, Hamdy N A, Farag A M and Fakhr I M I 2007 J. Chin. Chem. Soc. 541573

25. Yassin F A 2010 J. Microbiol. Antimicrob. 293

26. Cacic M, Trkovnik M, Cacic F and Has-Schon E 2006 Molecules 11134

27. Šarkanj B, Molnar M, Cacic M and Gille L 2013 Food Chem. 139488 